\title{
Vorwort zur 12. Auflage
}

Das Erscheinen der 12. Auflage (39.-42. Tausend) des „,Katechismus" gab dem Verfasser den Anlaß zu einer sorgfäJtigen Überarbeitung und Ergänzung des gesamten Stoffgebietes.

Hierbei wurde davon ausgegangen, da $\beta$ sich in den letzten Jahrzehnten hinsichtlich der bekannten und bewährten Wicklungsarten nichts Grundsätzliches geändert hat und voraussichtlich auch in absehbarer Zukunft keine nennenswerten diesbezüglichen Änderungen zu erwarten sind.

Richtungweisend waren vielmehr die Belange der Elektromaschinenbauer und Instandsetzer, die sich aus dem entwicklungsmäßig bedingten Fortschritt auf dem Sektor ,Elektromaschinenbau“, insbesondere aber aus dem allgemeinen Streben nach zeit- und kostensparenden Fertigungsmethoden zwangsläufig ergeben.

In der gegenwärtigen Zeit der Rationalisierung, Mechanisierung und Automatisierung steht die Einführung qualitätsverbessernder, zeit- und kostensparender Fertigungsmethoden im Vordergrunde der beruflichen Interessen. Hieraus ergab sich die Notwendigkeit, weiterhin Mittel und Wege aufzuzeigen, die zur Erreichung dieser Ziele beitragen können.

In diesem Sinne wurde die Zahl der Wicklungsschaltbilder in beachtlichem Umfang erhöht, Abbildungen der inzwischen auf dem Markt erschienenen, verbesserten Wickeleimaschinen und Hilfsmittel in den Fachtext eingefügt und über fortschrittliche Fertigungsmethoden in Wort und Bild berichtet.

Der Abschnitt „Instandsetzung von Kleinstmotoren“ wurde besonders sorgfältig überarbeitet und erheblich erweitert. Desgleichen wurde das Wickeldatenarchiv (Anhang) ausgebaut.

Der Verfasser steht in ständigem Erfahrungsaustausch mit Wickeleifachleuten des europäischen und überseeischen Auslandes. Die Berichte und Hinweise von dieser Seite wurden bei der Bearbeitung der vorliegenden I2. Auflage mit ausgewertet. Es soll aber an dieser Stelle auch erwähnt werden, daß sich der „,Katechismus" weit über die deutschen Grenzen hinaus viele neue Freunde erworben und auch hier zu einer fortschrittlichen Entwicklung in den Wickeleibetrieben beigetragen hat. 
Bei Erscheinen der vorliegenden 12. Auflage des „Katechismus“ blickt der Verfasser auf eine 37 jährige Tätigkeit als Fachschriftsteller und beratender Ingenieur zurück. In diesem langen Zeitraum sind viele tausend geistige und persönliche Kontakte entstanden, die den Verfasser veranlassen, seinem großen Leser- und Freundeskreis im In- und Ausland für das ihm entgegengebrachte Vertrauen zu danken. Dieser Dank gilt auch den Ratsuchenden, die dem Verfasser durch ihre Anfragen ständig neue Anregungen für seine fachschriftstellerische Tätigkeit gaben, sowie dem Verleger und seinen Mitarbeitern, die sich für die Gestaltung des vorliegenden Werkes einsetzten.

Krefeld, im Juli 1957

Der Verfasser 